\title{
The 10 Essential Shared Capabilities: a framework for mental health practice
}

\author{
Alison Brabban, University of Sunderland \\ Ian Mcconagle, CCAWI University of LIncoln \\ Charlie Brooker, CCAWJ University of Lincoln
}

\begin{abstract}
The 10 Essential Shared Capabilities (ESC) are a description of the core aspects of practice that support effective implementation and delivery of mental health care. The ESC have been derived directly from work with users, carers and mental health personnel. To support their introduction a learning pack was developed giving examples of the 10 ESC as they relate to current practice.

A pilot programme across England was developed to test the acceptability and potential utility of these materials and this paper reports on the evaluation of that pilot programme. Facilitators $(n=75)$ and learners $(n=579)$ were asked to rate each of the seven modules contained in the learning pack. A number of recommendations have been made to improve the materials that are being acted upon.
\end{abstract}

\section{Key words}

Essential Shared Capabilities; evaluation; pilot; learning materials

\section{Introduction}

The pace of change within mental health services, both statutory and non-statutory, presents a major challenge to education providers. As developments are taking place, new service models are emerging and the evidence base increasing. To keep pace with these changes training providers are faced with developing curricula that are responsive to the diversity of mental health provision that should be available in a modern service while ensuring the breadth of teaching does not compromise the depth of learning required.

It is widely acknowledged that education and training for mental health practice has not kept pace with contemporary service models or the changing needs of service users and carers (Brooker et al, 2002). It seems mental health training providers face a challenge to respond to the issues of service change and the associated change in the knowledge and skills base. The recent review by the Chief Nursing Officer on mental health nursing (Department of Health, 2006) gives a clear indication of the topography of modern mental health nursing. The review promotes care for all people of all ages and emphasises the diversity of mental health disorders that need to be treated. In addition, it recognises the variety of settings in which mental health care must be delivered including the criminal justice and primary care environments. The review also proposes that mental health nurses and their education providers should use this period of change to consider the value base underpinning the activity described above.

The attention placed on values-based practice appears to be justified. Despite significant advances in our understanding of mental health and an increase in the availability of psychological treatments, service users, their families and carers continue to complain that they are not listened to and little account is taken of their needs (Shepherd et al, 1995; Middleton et al, 2004). Service users and carers are seeking alternative approaches to care that promote recovery, social inclusion and citizenship. To ensure these issues are appropriately addressed there is an argument that all educational programmes should promote values as a foundation for all evidence-based care.

It is envisaged that the core curricula of all pre and post registration training, as well as training for the professionally non-affiliated workforce and mandatory and induction type training should be consistent with the 10 ESC. By making these fundamental to all mental health teaching there is considerable potential to promote education and training that ensures mental health care is responsive to the needs of service users, with day to day practice, based on sound values as well as an evidence base. In short, the ESC will assist in the delivery of a modern mental health service. This article briefly summarises the development of the 10 Essential Shared Capabilities. It then reports on a study that assessed the utility of a set of learning materials that were developed to introduce the $10 \mathrm{ESC}$ to those involved in mental health care. 


\section{The 10 Essential Shared Capabilities: a framework for mental health practice}

\section{Background to the development of the ESC learning pack}

Mental health currently represents one of the top clinical priorities in the NHS and major reforms have been unveiled to modernise health and social care (Department of Health, 2000; Department of Health, 1998a). A fundamental programme of reform has been outlined in the form of Modernising Mental Health Services (Department of Health, 1998b) and the National Service Framework (NSF) for mental health (Department of Health, 1999), which sets standards for mental health care across both health and social care.

The past few decades have also witnessed a shift in the provision of mental health services from the hospital setting to a range of community services, with an increasing emphasis on service user centred care, valuesbased and evidence-based practice. Much of mental health provision is located in partnership arrangements between trusts and social care services. In addition, a number of mental health trusts have applied for foundation status and will become masters of their own destiny, focused on delivering locally responsive services.

In 2001, the Workforce Action Team (WAT) began work to identify the knowledge, skills and attitudes that all staff working in mental health services should possess to deliver each of the NSF standards, from the core capabilities that the entire workforce should hold, to those competencies that should be held by specialist practitioners. The Capable Practitioner Framework (CPF) (Lindley et al, 2001) produced by the Sainsbury Centre provided some of this outline.

In addition to the CPF, the Workforce Action Team commissioned a piece of work to identify the capabilities of the current workforce in relation to the new vision for mental health delivery. A national exercise was conducted, which mapped mental health education and training across England (Brooker et al, 2002). This review demonstrated that mental health training provision was inadequate in relation to the delivery of the NSF and the NHS Plan. It appeared that training often had too narrow a clinical focus, and specific teaching on values implicit in service delivery and on socio-cultural aspects of care were often neglected. The findings were consistent with the concerns of service users and carers who complained that they were often not listened to, their contribution to mental health care was not valued and that care delivery was not conducted as collaboratively as possible.
The 10 Essential Shared Capabilities emerged from these two pieces of work as a joint National Institute of Mental Health in England (NIMHE) and Sainsbury Centre for Mental Health (SCMH) project. Guided by a national steering group, the programme was developed through consultation with service users, carers, managers, academics and practitioners. Spanning both values-based and evidence-based practice, the Essential Shared Capabilities provide an explicit benchmark of core attitudes, skills and knowledge for the entire mental health workforce. It is expected that these will be incorporated into individuals' appraisals and personal development plans and within all types of pre and post qualification training aimed at those working within mental health services. The 10 Essential Shared Capabilities (ESC) have been developed separately but complement two other existing skills frameworks, namely the Knowledge and Skills Framework (KSF) (Department of Health, 2004) and the National Occupational Standards for Mental Health (NOSMH) (see skillsforhealth.org.uk).

The Ten Essential Shared Capabilities Learning Pack for Mental Health Practice was developed to be piloted as part of an overarching implementation plan to introduce the mental health workforce to the core skills, attitudes and knowledge needed to deliver best practice. Commissioned by the NIMHE National Workforce Implementation Team and funded by the NHSU, the pack has an ambitious goal: to provide effective training to the entire mental health workforce spanning the different roles and qualifications, from those who are starting out in their training to experienced workers. In addition, the aim is to make the training interesting and accessible to this wide audience.

The ESC pilot programme contains learning materials in both CD-rom and paper format. The programme has an introductory guide followed by a central module on the ESC (see Appendix for an overview of the 10 items). There are four additional linked satellite modules on 'involving service users and carers', values-based practice', 'race equality and cultural capability' and 'developing socially inclusive practice'. A learning log or workbook accompanies each module and the programme ends with a personal action plan and learning review. The materials have been designed for either group or individual learning, and it was estimated, would take approximately 16 hours to complete. See Table 1 (over the page) for a description of the seven modules. 
The 10 Essential Shared Capabilities: a framework for mental health practice

Table 1: The seven modules of the 10 ESC pack

\begin{tabular}{|c|c|}
\hline Module 1 & Getting Started - guidance notes on using the learning pack for facilitators and learners \\
\hline Module 2 & The Ten Essential Shared Capabilities - An overview of all the 10 ESC \\
\hline Module 3 & $\begin{array}{l}\text { Involving Service Users and Carers - A review of the } 10 \text { ESC in working with the similarities and } \\
\text { different needs of service users and carers }\end{array}$ \\
\hline Module 4 & Values-based Practice - Using the ESC to work positively with diversity and differences of values \\
\hline Module 5 & $\begin{array}{l}\text { Race Equality and Cultural Capability - Promoting understanding of the connections between } \\
\text { race, culture, mental health and the } 10 \mathrm{ESC}\end{array}$ \\
\hline Module 6 & $\begin{array}{l}\text { Developing Socially Inclusive Practice - Using the } 10 \text { ESC to challenge the processes that lead to } \\
\text { inequality and exclusion }\end{array}$ \\
\hline Module 7 & Personal Action Plan and Learning Review - The 10 ESC Self assessment and action planning \\
\hline
\end{tabular}

The CD-rom is interactive and provides reading as well as practical exercises that need be carried out. In addition, the CD-rom provides links to useful websites and contains a library of relevant documents that the learner may wish to access. The materials can be used in a stand-alone fashion or can be integrated into existing training programmes.

\section{Evaluation}

The learning materials also contained a brief self-report evaluation questionnaire and this paper reports on the collated data. Given that the learner cohorts were made up of a range of mental health personnel from statutory and non-statutory sectors and from professionally qualified to professionally aligned groups, the evaluation gives a perspective on how these people responded to the materials from an inter-disciplinary perspective. It has been suggested that inter-professional education occurs when two or more professions come to learn from each other and together (Barr et al, 2005). While the authors can report on how professionals and others responded to the same materials we are not in a position to report on the 'professional' or health care worker make up of the learner groups. This limits the results from an inter-professional basis and the self report nature of the evaluation limits what can be deduced on the impact on practice of the ESC learner pack.

\section{Method \\ Design}

The National Health Service University (later closed in November 2004) held the initial project management of the ESC programme and through an 'expression of interest' process identified over 60 possible pilot sites where there was a willingness to test the ESC learning materials. Following closure of the NHSU the project was transferred for co-ordination to one of the authors (McGonagle) and organised in close liaison with the eight NIMHE Regional Development Centre leads. Local training facilitators, either service user trainers, university lecturers or organisation 'in-service trainers' were recruited to the pilot. They were nominated by each pilot site organisation as competent training facilitators. The eight Regional Development Centre leads played a significant role in supporting these local training facilitators (see above) in each of the pilot sites. The recruited sites received the ESC packs in September 2005 and were asked to complete the programme by mid December 2005.

\section{Procedure}

Evaluation forms (or questionnaires) for learners and facilitators were incorporated into each of the 10 ESC learner packs. The evaluation forms were part and parcel 


\section{The 10 Essential Shared Capabilities: a framework for mental health practice}

of the whole training pack and incorporated into module 7 (Action Planning). All completed questionnaires were collected by one of the authors (IMcG) prior to passing on to the evaluation team $(A B \& C B)$. The evaluation questionnaire contained requests for demographic information and self report perceptions on acceptability of the learning materials. As noted earlier the limits within the questionnaire method did not facilitate detailed understanding on how professionals and other workers in mental health compare their perspectives and value base in mental health practice.

The self-report questionnaire methodology was favoured due to the size of the project and the information requested. The project team were keen to obtain a general understanding of people's acceptance of the learning materials as an approach to foundation learning about Essential Shared Capability training. The project team believed that provision of numerical scoring of the modules and opportunity to write considered responses to the exercises and modules was sufficient for the project aims.

\section{Evaluation method}

The questionnaire asked both learners and trainers to rate statements relating to the training materials on a Likert scale with four categories, namely 'agree strongly', 'agree slightly', 'disagree slightly' and 'disagree strongly'. In addition the questionnaire prompted respondents to qualify ratings and to comment on the learning materials.

\section{Sample}

The sample was opportunistic with 60 sites indicating originally that 1,075 individual learners would participate in the testing of the materials. A total 46 sites (77\%) and 579 (54\%) individuals participated. The site drop out rate could be explained by the challenging timescale for project completion. A number of sites stated that due to organisational pressures (re-structuring etc.), they were unable to participate in the study. The sample was drawn from each of the CSIP/NIMHE regions in England. There was a range of sample groups in these sites from 13 in one site and four in another. However, there was no significant difference in the number of drop outs and completers between the regions.

\section{Analysis Statistical analysis}

Data collected on the two questionnaires (learner feedback questionnaire and facilitatator feedback) were separately double entered onto a computer database and data entry errors were identified by matching the data entry files using the epidemiological software Epi-Info. All errors were corrected with reference to the original questionnaires and a final validated data file produced. Data analysis was then undertaken using the software SPSS version 11.5.

The only statistical test employed was the chi-square test. This was used to test whether, for categorical data, there were differences between groups including those from different professional backgrounds, those following different styles of learning and those from different ethnic groups.

\section{Analysis of qualitative data}

There were several opportunities in the questionnaires for both learners and facilitators to answer 'open' questions. Responses that illuminated important aspects of the quantitative evaluation are reported in an attempt to measure or 'unpack' the numeric data.

\section{Results}

A total of 579 questionnaires were returned from learners and 75 from facilitators. Responses came from 46 of the 60 sites that had originally agreed to participate in the pilot study including mental health NHS trusts, primary care trusts, social services, higher education institutions and housing agencies.

Demographic details of respondents can be seen in Table 2 (over the page). Over two-thirds of both the learners and facilitators were female. Respondents were from all age groups and from a mix of ethnic backgrounds. Approximately one-quarter of learners and facilitators were from a minority ethnic group. Over twothirds of the learners were NHS workers compared to less than half of the facilitators and over $45 \%$ of both groups held a professional qualification or a degree. There was wide variation in the professional background of the learners, though $42 \%$ of the overall sample was made up of nurses and support workers. 
Table 2: Demographics of learners and facilitators

\begin{tabular}{|c|c|c|}
\hline & Learners & Facilitators \\
\hline Gender & Male 30\%; Female $70 \%$ & Male 30\%; Female 70\% \\
\hline Age range (mode) & $16-65+(35-44)$ & $16-64(45-54)$ \\
\hline \multicolumn{3}{|l|}{ Ethnic group (\%) } \\
\hline White & 451 (78) & $56(75)$ \\
\hline Asian & $49(8.5)$ & $6 \quad(8)$ \\
\hline Black & $49(8.5)$ & $8(11)$ \\
\hline Mixed & $14 \quad(2)$ & $1 \quad(1)$ \\
\hline Other & $7 \quad(1)$ & \\
\hline Missing & $9 \quad(2)$ & $4 \quad(5)$ \\
\hline \multicolumn{3}{|l|}{ Capacity (\%) } \\
\hline NHS & $400 \quad(69)$ & $34(45)$ \\
\hline Voluntary sector & $57(10)$ & $3 \quad(4)$ \\
\hline Social services & $27 \quad(5)$ & $6 \quad(8)$ \\
\hline Service user & $18 \quad(3)$ & $13(17)$ \\
\hline Carer & $35 \quad(6)$ & $5 \quad(7)$ \\
\hline Other & $20 \quad(4)$ & $9(12)$ \\
\hline \multicolumn{3}{|c|}{ Highest educational qualification } \\
\hline Professional qualification & $146(25)$ & $31(41)$ \\
\hline Degree & 130 & $25(33)$ \\
\hline Diploma & $55(10)$ & $8(11)$ \\
\hline Certificate & $97(17)$ & $5 \quad(7)$ \\
\hline NVQ & $77(13)$ & $6 \quad(8)$ \\
\hline No qualification & $41 \quad(7)$ & \\
\hline Missing & $33 \quad(6)$ & \\
\hline \multicolumn{3}{|l|}{ Professional background } \\
\hline Nurse & 121 & - \\
\hline Support worker & $122(21)$ & - \\
\hline Occupational therapist & $34 \quad(6)$ & - \\
\hline Student nurse & $29 \quad(5)$ & - \\
\hline Social worker & $15 \quad$ (3) & - \\
\hline Housing support worker & $17 \quad(3)$ & - \\
\hline Service user & $15 \quad(3)$ & - \\
\hline Carer & $26 \quad(5)$ & - \\
\hline Admin staff & 21 & - \\
\hline Other* & $145(42)$ & - \\
\hline Missing & $34 \quad(6)$ & - \\
\hline
\end{tabular}

* Includes student social worker, student occupational therapists, chaplains, CDWs, psychologists, medics etc. (each individual group represents $<2 \%$ of overall sample). 


\section{The 10 Essential Shared Capabilities: a framework for mental health practice}

\section{Mode of delivery}

$82 \%(n=557)$ of the learners reported that the training materials had been delivered by a facilitator within a group setting. Less than two-thirds of those who responded commented on the method of delivery. However, of those who did only $2 \%(n=12)$ had relied solely on the CD-rom and over half $(n=200)$ had used only the paper materials.

Of those 179 learners who reported use of the CDROM (either alone or in addition to the paper materials), $70 \%$ of this number had done so without experiencing any technical problems.

\section{The training materials Learners ratings}

Learners were asked to rate statements relating to the training materials on a Likert scale with four categories, namely 'agree strongly', 'agree slightly', 'disagree slightly' and 'disagree strongly'. Figure 1 displays the percentage of respondents rating who agreed with the statements either 'strongly' or 'slightly'. The clarity of the materials, the availability of necessary information to use the materials, the style of delivery, the environment in which the materials were delivered, and enjoyment of using the materials were all rated highly, with over $80 \%$ of the learners providing positive responses.
The level at which the programme was pitched, the level of support and the organisation of the programme were again rated highly, though over $20 \%$ of respondents did provide a negative response about these elements on the Likert scale and reported some level of disagreement with the statement 'the programme was pitched at the right level'.

When the ratings of the 'level of the programme' were divided into professional groupings it became apparent that certain groups were more positive about the level than others (see Figure 2 - over the page). Although 100\% of student nurses and housing support workers were in agreement that the programme was pitched at the right level, less than $50 \%$ of administrative workers shared this view. It is not surprising that those not working face-to-face with service users felt that the training was less appropriate for them as so much of the material asks participants to draw on such experiences. Similarly, over a third of service users and carers were of the opinion that the level of the materials was not appropriate for them. Comments from a number of service users and carers such as the one below suggest some believed that a relevant role for service users and carers was to facilitate the learning itself.

'It is very important that service users and carers contimue to play an important part in the delivery of the programme no matter what form it takes.'

\section{Figure 1: Learners' ratings of the training programme}

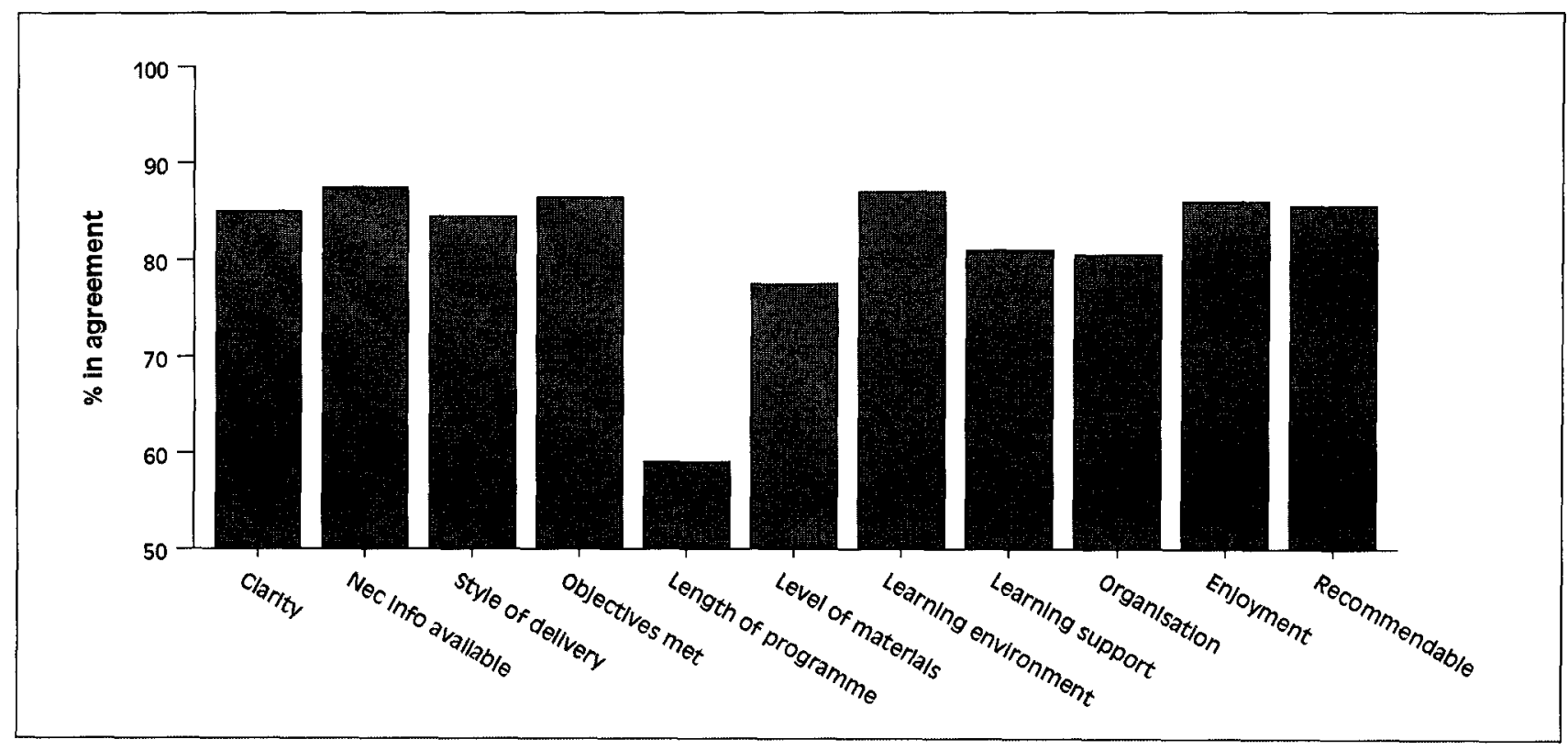


Figure 2: Percentage of respondents endorsing appropriateness of the level of the programme by professional grouping

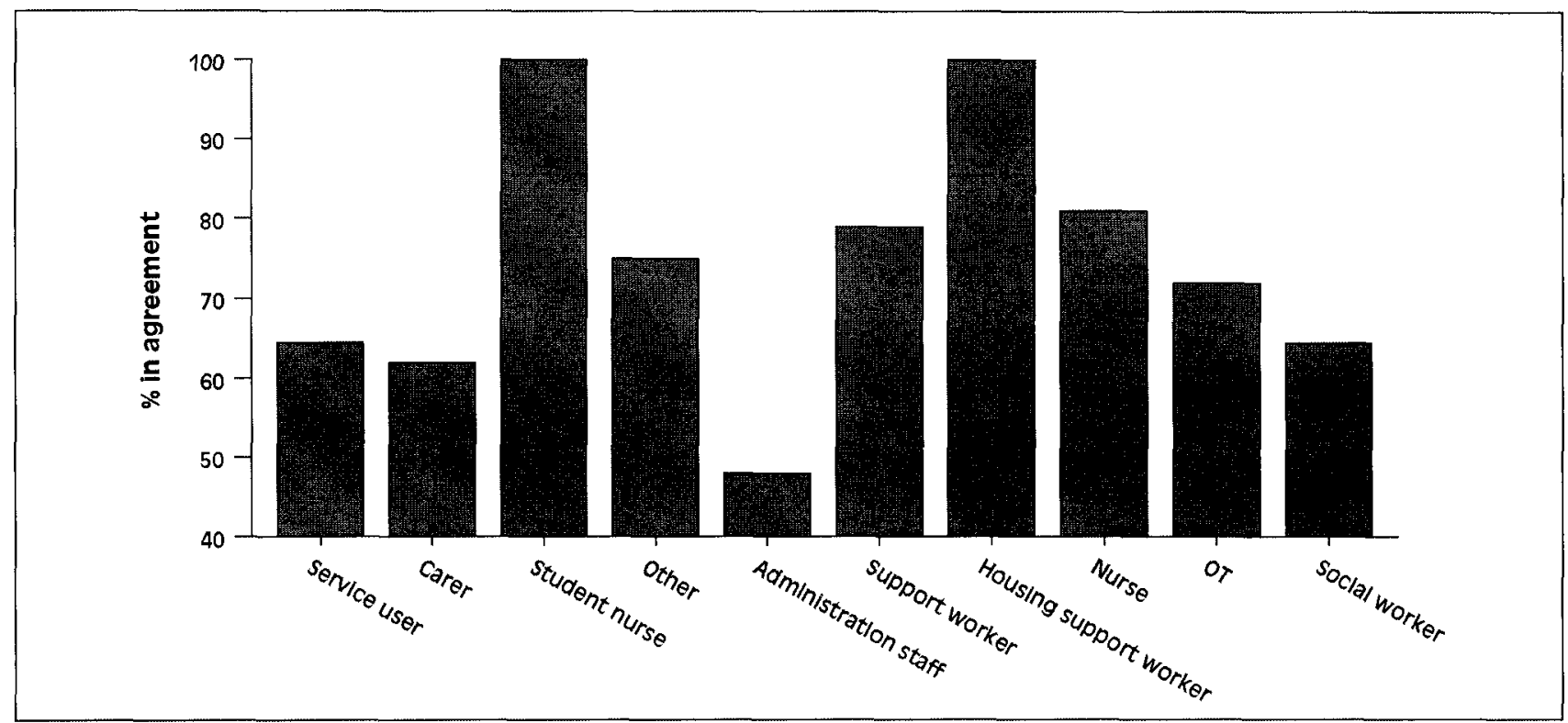

The service setting of the participants also impacted upon overall evaluation of the content. Qualitative feedback from a number of learners who worked in primary care felt that examples given were too focused on adults receiving secondary service provision.

Overall, the length of the training programme received the most negative endorsements, with $60 \%$ of learners disagreeing with the statement that 'the programme was the right length for $\mathrm{me}^{\prime}$. Of the comments made on the delivery of materials, the majority complained that the programme had taken much longer to complete than had been suggested. Feedback indicated that this could be reduced by minimising repetition of exercises that occurred between modules.

The style of delivery impacted greatly upon the ratings of a number of the above elements of the programme ie. whether the learner had undergone the training alone or as part of a group programme. Chi-square analyses revealed that those who had studied alone were significantly more likely to disagree with the statements relating to the appropriateness of the 'style of delivery' (individual or group) $\left(X^{2}=83.1\right.$, d.f.=1, $\left.p<0.001\right)$, 'the level of the programme' $\left(X^{2}=7.06\right.$, d.f. $\left.=1, p=0.008\right)$, the 'environment where the learning took place' $\left(\mathrm{X}^{2}=24.1\right.$, d.f. $\left.=1, \mathrm{p}<0.001\right)$ and the 'support received'
$\left(X^{2}=13.90\right.$, d.f. $\left.=1, p<0.001\right)$. In addition, many learners and facilitators fed back concerns about 'quality control' issues when studying independently and most who commented on the style of delivery believed the materials should be used within a group setting. Without a group available for discussion, it was felt there was no way of determining whether exercises and responses were being answered appropriately and learning was taking place in the required direction.

\section{Facilitator ratings}

Ratings of the materials by facilitators were also positive, with over $70 \%$ of respondents providing a positive rating for all but the length of the programme. In keeping with the responses of the learners however, the length of the programme was rated most negatively with over a third of respondents disagreeing with the appropriateness of this. Over $85 \%$ of the facilitators provided a positive endorsement to statements on the clarity of materials, that the materials supported flexible delivery, on the relevance of the learning outcomes, the achievability of the outcomes and the enjoyment of the learning experience. A high proportion also rated the materials as addressing diversity and equality issues appropriately and also encouraging service user and carer involvement. 


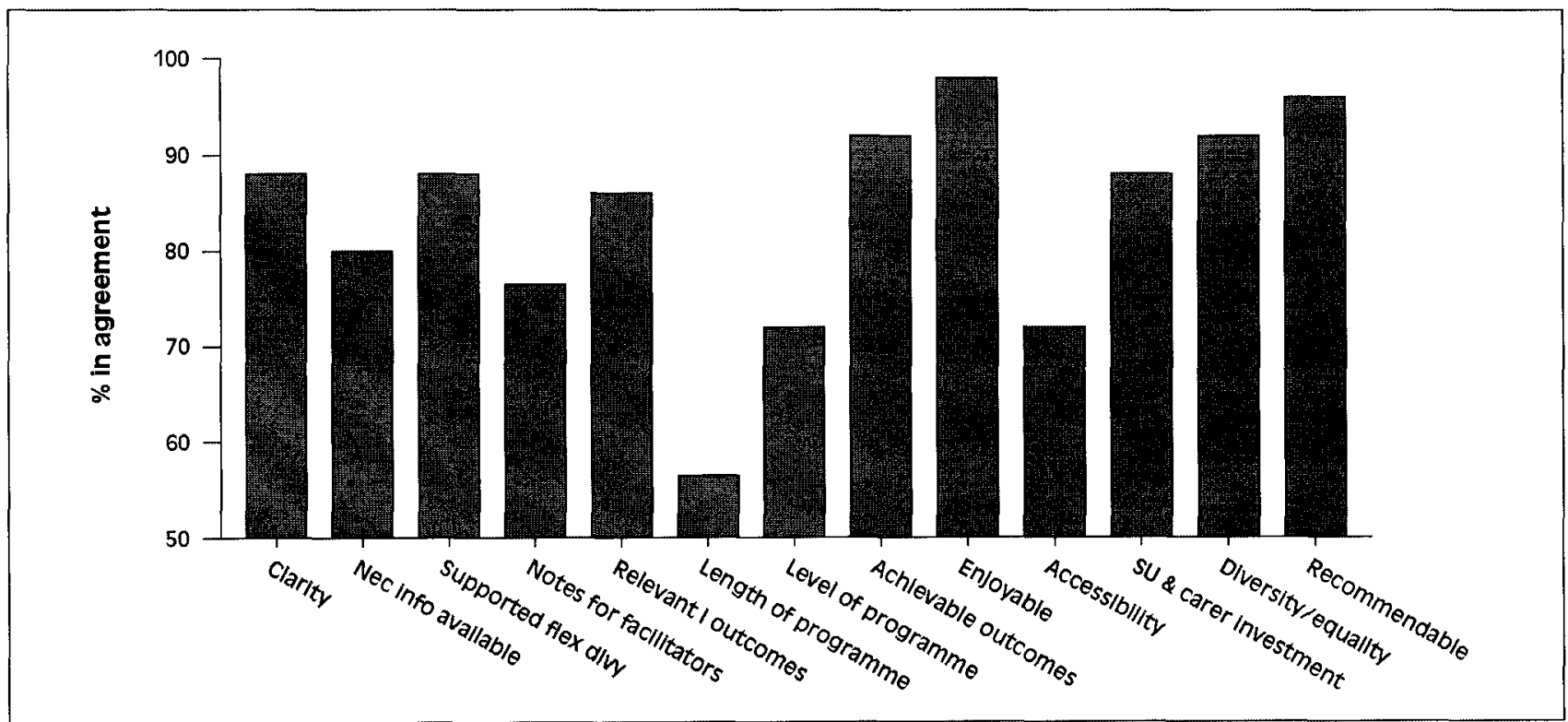

In relation to accessibility, there was consistent feedback that the materials appeared to be targeting clinical practitioners working in secondary care services. Comments suggested that they were less accessible to those working in primary care and many non-clinicians, especially administrative staff who found them difficult to use.

\section{Module ratings}

\section{Learners' ratings of the seven modules}

Learners were asked to rate each module on a Likert scale with four points namely 'unsatisfactory', 'satisfactory', 'good' and 'excellent'. Overall the modules were received very positively with $70 \%$ or more of the learners rating modules two (the Ten Essential Shared Capabilities), three (Involving Service Users and Carers), four (Values-based Practice) and six (Developing Socially Inclusive Practice) as either 'good' or 'excellent'. Of these modules three and six received the highest rating. Respondents were least satisfied with modules five (Race Equality and Cultural Capability) and seven (Personal Action Plan and Learning Review), with over a third of them rating these as either 'satisfactory' or 'unsatisfactory'. Figure 4 shows the percentage of learners and facilitators rating each module as either 'good' or 'excellent'.
Qualitative feedback on module five on race equality and cultural capability was extremely diverse. Many learners found it 'difficult' and 'heavy going' but felt their thinking had been challenged. The qualitative results of the ratings of this module were examined to see whether any differences were apparent between learners with different cultural backgrounds. In general, black and Asian learners were more satisfied with this module than white learners and those of mixed race. When these groups were combined, it was found that the ratings from black and Asian learners were significantly higher than the other two groups $\left(X^{2}=6.09\right.$, d.f. $\left.=1, p=0.01\right)$.

There was also mixed written qualitative feedback on module seven (Personal Action Plan and Learning Review). Those who rated this module highly found it 'useful', 'detailed' and 'helpful with Knowledge and Skills Framework (KSF) appraisal' however, many learners found the module 'confusing', 'complicated', 'over long' and 'too labour intensive'. A number of respondents believed this module should have been introduced in module one rather than left till the end.

When the professional background of learners was considered it was found that the majority of student nurses and housing support workers were most satisfied with each of the modules, and administrative staff and occupational therapists were the least satisfied. 


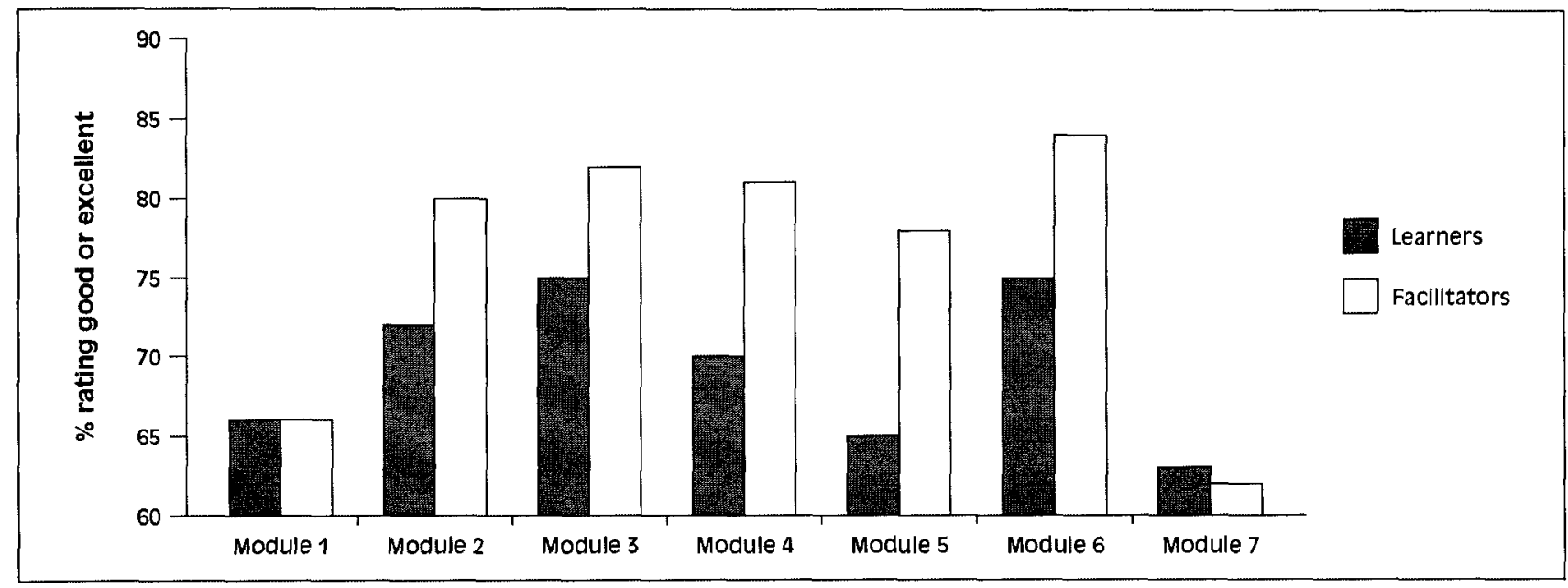

\section{Facilitators' ratings of the seven modules}

Facilitators rated each of the seven modules on the same Likert scale as the learners. Facilitators rating of the modules, shown in Figure 4, demonstrate that they were extremely positive towards most of the modules. Only modules one (Getting Started) and seven (Personal Action Plan) had more than $30 \%$ of respondents rating them as below 'good'. Facilitators did not show the same level of dissatisfaction with module five as the learners, only $22 \%$ rated this module as less than 'good' compared to $35 \%$ of the learners.

\section{Impact and Overall Rating Learners' ratings}

In total, 90\% of learners who rated the materials agreed (either 'strongly' or 'slightly') that the materials had impacted on the way they thought about and worked with service users with mental health problems. When responses were compared to the professional group there were some differences. The entire group of student nurses who rated the materials $(n=29)$ believed that the materials would make a difference to the way they worked whereas $20 \%(n=14)$ of social workers were not convinced that this was the case.

When rated overall, the programme was well received. Eighty per cent of learners $(n=486)$ rated learning materials as either good or excellent. Once again there was some variation in satisfaction between professional groups. The entire group of student nurses rated the programme as good or excellent compared to only $55 \%$ of the administrative staff $(n=21)$ and $62 \%$ of occupational therapists $(n=26)$.

In addition, $29 \%$ of learners who had undertaken learning on their own rated the materials overall as either 'acceptable' or 'poor' compared to only $17 \%$ who had been part of a group. A chi-square analysis revealed this difference as highly significant $\left(X^{2}=7.65 ;\right.$ d. $\left.f=1 ; p=0.006\right)$.

\section{Facilitators' ratings}

In response to a statement asking facilitators to rate whether the learning programme had impacted on the way the learners would work with service users, 95\% agreed that this was the case (slightly or strongly). They were also very positive when rating the programme overall. None of the 70 facilitators who rated the materials rated them as 'poor' and $85 \%$ rated them as good or excellent.

\section{Discussion}

The ESC learning materials pilot was conducted over a four month period and presented an appreciable commitment from participating organisations. Significantly, the management of the learning materials project was handed over from the dissolved NHSU with associated project transfer difficulties such as maintenance of communication with pilot site co-ordinators and regional leads.

The learning materials were aimed at all personnel in mental health settings regardless of educational or professional background. The materials can be used flexibly (either as a paper resource; CD-ROM or combination, used 


\section{The 10 Essential Shared Capabilities: a framework for mental health practice}

as a group resource or for individual learning. The results indicate that personnel from mental health services from across the spectrum of roles rated the materials highly. Additional materials that take participants deeper into the subject matter of the ESC and practice applications are being developed by the National Institute for Mental Health in England. It is envisaged that the materials reported here will form the foundation of a suite of materials, which as a whole will form the basis of training materials for all mental health services. Evaluation of impact of such learning programmes remains an important aspect of planning and implementation of programmes such as these. The results presented here indicate that there was acceptance of the materials as a useful and helpful resource. Whether the use of such materials can help practitioners continuously improve their practice still requires longer-term investigation.

The opportunity for comparative inter-professional education around the values of mental health care also exists within the framework of the 10 Essential Shared Capabilities. The project aims of this pilot programme did not lend themselves for detailed analysis of this important aspect of health care delivery. The authors suggest that the ESC do present an opportunity for educationalists and researchers to investigate differences and similarities of values behind mental health workforce practice. In this study different professional groups reported different levels of acceptance of the materials with student nurses and housing support workers differing from others, and some differences between professionally qualified groups (see Figure 3). Again these self report differences need more detailed investigation and analysis.

Therefore, although the flexibility of this distance learning package is advantageous in that it allows for individuals to learn in their own time and at their own pace, it would seem important for learners to have contact with a tutor or mentor to ensure appropriate learning has taken place.

\section{Conclusion}

The overall evaluation of the pilot ESC training programmes was highly positive. Learners and facilitators/ mentors rated nearly all aspects of the programme highly (see Figures 1 and 3), including: the clarity of the materials, style of delivery, the extent to which the programme met their learning objectives, the level of the materials, the learning and organisational support and their enjoyment in participating. There was also widespread agreement that generally, the individual modules were successful in meeting their aims, although it is important to note that facilitators' ratings were higher than learners' ratings in this regard (see Figure 4). It should also be noted that two modules in particular (module five on race equality and cultural capability and module seven on personal action plan and learning review) received substantially less favourable feedback from learners. The respondents reported that module five (race equality) did not emphasise the full range of BME populations and required care studies as illustrations. Module seven (Personal Action Plan) was reported as too difficult to follow and did not support respondents in their learning.

In this context, perhaps what is most important to emphasise is that $90 \%$ of learners, and $95 \%$ of facilitators agreed that the learning undertaken would impact upon the way that practitioners would work with service users and carers. The nature of this study does not allow any statements to be made on any actual change on role performance and value base of learners involved in the study. It is clear from results that positive learning and engagement in the programme took place, gleaned from a healthy questionnaire response rate from sites and learners.

This pilot programme was designed to provide data to base further enhanced iterations of the 10 ESC learning materials. In light of the findings, a number of changes are being implemented (ie. rewording the material to ensure applicability to the entire mental health workforce, such as administrative staff, and not just clinical/practice ones).

The ESC pilot programme has proved successful in engaging large numbers of personnel in discussing, challenging and supporting the competing value bases underpinning mental health practice.

\section{Address for correspondence}

Ian McGonagle

Centre for Clinical and Academic Workforce Innovation (CCAWI)

Floor 2 Mill 3, Pleasley Vale Business Park

Outgang Lane

Mansfield

NG19 8RL

Email: imcgonagle@lincoln.ac.uk 
The 10 Essential Shared Capabilities: a framework for mental health practice

\section{References}

Barr H, Koppel I, Reeves S, Hammick M \& Freeth D (2005) Effective Interprofessional Education: Argument, Assumption and Evidence. Oxford: Blackwell.

Brooker C, Gournay K, O’Halloran P \& Bailey D (2002) Mapping training to support the implementation of the National Service Framework for Mental Health. Journal of Mental Health 11 (1) 103-116.

Department of Health (1998a) Modernising Social Services: Promoting Independence. London: Department of Health.

Department of Health (1998b) Modernising Mental Health Services: Safe, Sound \& Supportive. London: Department of Health

Department of Health (1999) A National Service Framework for Mental Health: Modern Standards and Service Models. London: Department of Health.

Department of Health (2000) The NHS Plan: A plan for investment, a plan for reform. London: Department of Health.

Department of Health (2004) The NHS Knowledge and Skills Framework (NHS KSF) and the Development Review Process. London: Department of Health.
Department of Health (2006) From Values to Action: the Chief Nursing Officer's Review of Mental Health Nursing. London: Department of Health.

Lindley P, O'Halloran P \& Juriansz D (2001) The Capable Practitioner. A framework and list of the practitioner capabilities to implement the National Service Framework for mental health. London: Sainsbury Centre for Mental Health.

Middleton P, Stanton P \& Renouf N (2004) Consumer Consultants in Mental Health Services: Addressing the Challenges. Journal of Mental Health 13 (5) 507-518.

National Occupational Standards for Mental Health (2006) [online]. Available from: www.skillsforhealth.org.

Sainsbury Centre for Mental Health (1997) Pulling Together: The Future Roles and Training of Mental Health Staff. London: Sainsbury Centre for Mental Health.

Shepherd G, Murray A \& Muijen M (1995) Perspectives on Schizophrenia: A Survey of User, Family Carer and Professional Views Regarding Effective Care. Joumal of Mental Health 4 (4) $403-422$. 


\section{Appendix}

\section{The 10 Essential Shared Capabilities for mental health practice}

\section{Working in partnership}

Developing and maintaining constructive working relationships with service users, carers, families, colleagues, lay people and wider community networks. Working positively with any tensions created by conflicts of interest or aspiration that may arise between the partners in care.

\section{Respecting diversity}

Working in partnership with service users, carers, families and colleagues to provide care and interventions that not only make a positive difference but also do so in ways that respect and value diversity including age, race, culture, disability, gender, spirituality and sexuality.

\section{Practising ethically}

Recognising the rights and aspirations of service users and their families, acknowledging power differentials and minimising them whenever possible. Providing treatment and care that is accountable to service users and carers within the boundaries prescribed by national (professional), legal and local codes of ethical practice.

\section{Challenging inequality}

Addressing the causes and consequences of stigma, discrimination, social inequality and exclusion on service users, carers and mental health services. Creating, developing or maintaining valued social roles for people in the communities they come from.

\section{Promoting recovery}

Working in partnership to provide care and treatment that enables service users and carers to tackle mental health problems with hope and optimism and to work towards a valued lifestyle within and beyond the limits of any mental health problem.

\section{Identifying people's needs and strengths}

Working in partnership to gather information to agree health and social care needs in the context of the preferred lifestyle and aspirations of service users, their families, carers and friends.

\section{Providing service user centred care}

Negotiating achievable and meaningful goals; primarily from the perspective of service users and their families. Influencing and seeking the means to achieve these goals and clarifying the responsibilities of the people who will provide any help that is needed, including systematically evaluating outcomes and achievements.

\section{Making a difference}

Facilitating access to and delivering the best quality, evidence-based and values-based health and social care interventions to meet the needs and aspirations of service users, their families and carers.

\section{Promoting safety and positive risk taking}

Empowering the person to decide the level of risk they are prepared to take with their health and safety. This includes working with the tension between promoting safety and positive risk taking, including assessing and dealing with possible risks for service users, carers, family members, and the wider public.

\section{Personal development and learning}

Keeping up-to-date with changes in practice and participating in life-long learning, personal and professional development for one's self and colleagues through supervision, appraisal and reflective practice. 
SHELFMARK: TITLE:

\subsection{SOH-6885S WORKFORCE DEVELOPMENT STRATEGIES.}

Date Submitted: Date Printed:

YEAR: 2006

VOLUME/PART: 2006 VOL1 PT3 PP2 - 4

\title{
PAGES:
}

AUTHOR:

\section{ARTICLE TITLE:}

RZRAE015COPYRT|JOURNAL OF MENTAL HEALTH=20|WORKFORCE DEVELOPMENT|2006 VOL1 PT3 PP2 4|THE 10 ESSENTIAL SHARE CAPABILITIES: $=20 \mid$ A FRAMEWORK FOR MENTAL. HEALTH

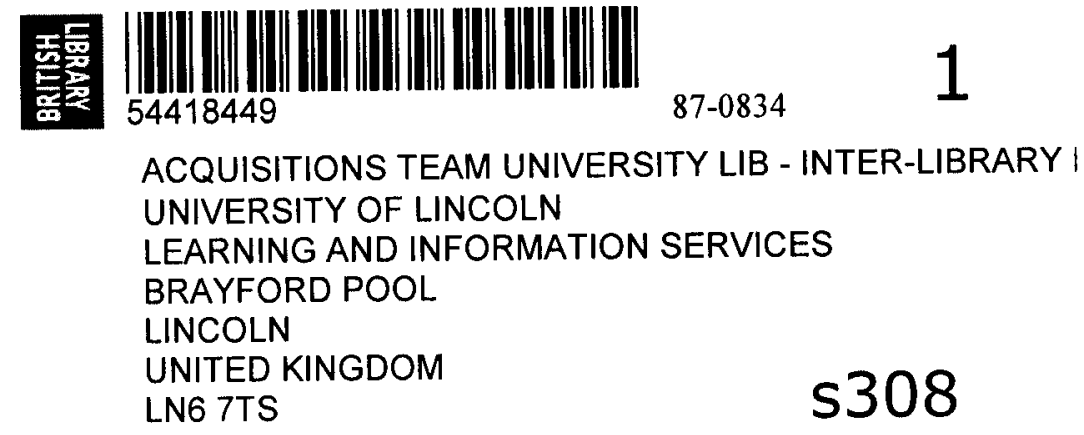

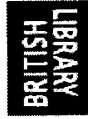

\section{s308}

REG-24015235

Return Date

Request Ref. No.

RZRAE015COPYRT

If no other library indicated please return loan to:-

The British Library Document Supply Centre, Boston Spa, Wetherby, West Yorkshire, United Kingdom LS23 7BQ

\section{DELIVERING THE WORLD'S KNOWLEDGE}

\author{
THIS DOCUMENT HAS BEEN SUPPLIED BY THE BRITISH LIBRARY \\ www.bl.uk
}

The contents of the attached document are copyright works. Unless you have the permission of the copyright owner, the Copyright Licensing Agency Ltd or another authorised licensing body, you may not copy, store in any electronic medium of otherwise reproduce or resell any of the content, even for internal purpose, except as may be allowed by law.

If the request form above has the word 'Copyright' written in large text, it was supplied under our Copyright Fee Paid service. You are therefore agreeing to the terms of supply for our Copyright Fee Paid service, available at www.bl.uk/service/document/edd.html.

If the request form above does not have the word 'Copyright' written in large text, it was supplied for our Library Privilege service. You are therefore agreeing to the terms of supply for our Library Privilege service, available at www.bl.uk/service/documents/LPS.html. 